\title{
Distribution of calcium, nickel, iron, and manganese in super-heavy oil from Liaohe Oilfield, China
}

\author{
Wu Bencheng*, Zhu Jianhua and Li Xiaohui \\ College of Chemical Engineering, China University of Petroleum, Beijing 102249, China \\ (C) China University of Petroleum (Beijing) and Springer-Verlag Berlin Heidelberg 2014
}

\begin{abstract}
Liaohe super-heavy crude oil was separated into its components, namely saturates, aromatics, resins, and asphaltenes (SARA), by the group separation method. Several solvents were used to extract different forms of metallic elements from crude oil. The metallic elements, such as calcium, nickel, iron and manganese, in crude oil, SARA and extract samples were analyzed by inductively coupled plasma atomic emission spectroscopy (ICP-AES). The results demonstrate that the contents of calcium, nickel, iron, and manganese gradually increase in saturates, aromatics, resins, and asphaltenes, suggesting that the abundance of the four metallic elements in asphaltenes is much higher than that in the other groups. For example, the content of calcium in asphaltenes reaches a maximum of 7,920 $\mu \mathrm{g} / \mathrm{g}$. Among the SARA components of Liaohe super-heavy crude oil, resins account for more than $50 \mathrm{wt} \%$, suggesting that the total amount of the four metallic elements are higher in the resin component than in other components. The four metallic elements mainly exist in the form of organic metallic compounds in crude oil. Further analysis shows that calcium and manganese elements exist mainly as metal salts of petroleum acids, and the majority of the iron and all the nickel exist mainly as metalloporphyrin and non-metalloporphyrin compounds.
\end{abstract}

Key words: Super-heavy oil, metallic element, distribution, group separation, solvent extraction

\section{Introduction}

Almost all known metallic elements can be detected in crude oil, resulting in heterogeneous catalyst deactivation through different mechanisms in the petroleum catalytic processing (Bartholomew, 2001; Trimm, 2001). The presence of metallic elements in crude oil results in low-quality oil products. For instance, the high metallic content in coke leads to high ash content, which decreases the economic return to the petroleum companies (Luo et al, 2005). Moreover, the metallic elements in crude oil can foul and corrode the refinery equipment and pipelines. In recent years, with the increased production of heavy and low-quality crude oil, the potential hazard in petroleum processing becomes more serious because of the high metallic content of crude oil.

Nickel and vanadium are common in crude oil or its residues. Numerous researchers (Krasnikov et al, 2007; McKenna et al, 2009; El-Sabagh, 1998; Xu et al, 2001) have studied the distributions of nickel and vanadium and the mechanisms of catalyst deactivation by them. However, studies on other metallic elements, such as calcium, iron, and manganese, are rarely reported. Zhu and Wang (1998)

*Corresponding author. email: wu_bc@cup.edu.cn

Received January 10, 2014 have reported that high calcium content is a characteristic of most Chinese crude oil. For example, the calcium contents of Jidong crude oil from Huabei oilfield, Gudong crude oil from Shengli oilfield, and Karamay crude oil from Xinjiang oilfield are 340,238 , and $143 \mu \mathrm{g} / \mathrm{g}$, respectively.

There is a conventional perspective that all the calcium in crude oil or residue exists in the form of inorganic salts, such as $\mathrm{CaCl}_{2}, \mathrm{Ca}(\mathrm{OH})_{2}$, or $\mathrm{CaCO}_{3}$. However, this has been proven to be a misconception. Wu et al (2001) have demonstrated that water-soluble calcium and oil-soluble calcium co-exist in Karamay vacuum residue, in which the oil-soluble calcium is mainly present as calcium salts of carboxylic acids. Hou and Wang (2000) have studied Zhongyuan, Liaohe, Jidong, and Dagang crude oils and found that the percentage of the watersoluble calcium is low especially in the crude oils with high calcium content.

Liquid-solid adsorption chromatography (LSAC) is usually utilized for group separation of crude oil or residue. Although LSAC is considered to be laborious and time-consuming compared with high-performance liquid chromatography, it is still extensively used because of its standardized procedure and low-cost equipment. Liu et al (2000) have utilized LSAC to perform group separation for Liaohe super-heavy oil and found that $48.6 \%$ of the calcium content cannot be washed off from the chromatographic 
column because organic calcium tends to be absorbed by the alumina column. Similar results have also been reported (Zhu and Wang, 1998; Hou and Wang, 2000).

To avoid the loss of metallic elements in the LSAC method, the solvent method was applied for the group separation of Liaohe super-heavy oil in this work. The distribution of metallic elements in saturates, aromatics, resins and asphaltenes (SARA) was obtained. In addition, the calcium, nickel, iron, and manganese elements in Liaohe super-heavy oil were investigated with the extraction method using different solvents.

\section{Experimental}

\subsection{Sample}

The super-heavy oil from the Liaohe oilfield in Northeast China is typical Chinese heavy oil with low maturity and serious biodegradation. According to the national classification standard of China for crude oil, the Liaohe super-heavy oil is classified into low-sulfur naphthene-based crude oil.

\subsection{Experimental procedure}

\subsubsection{Distribution of metallic elements in group fractions} of Liaohe super-heavy oil

Group separation is necessary in the study of the distribution of metallic elements in the fractions of Liaohe super-heavy oil. Instead of the LSAC method, the solvent method was applied to separate crude oil into four components: saturates, asphaltenes, resins, and aromatics. The separation procedures are briefly described as follows:

1) The asphaltenes of crude oil were precipitated using $n$-heptane according to the standard test method (China) SH/T 0266-1992 (determination of asphaltene content in petroleum). The insoluble components (asphaltenes) were separated from the liquid phase of the maltene fraction by filtration.

2) The acetone-insoluble resin components were obtained from maltene after acetone extraction.

3) The dimethylformamide-insoluble aromatic components were isolated from the liquid phase obtained in step (2), and the saturate components were obtained from the remaining matter after solvent evaporation in an oil bath at constant temperature.

Finally, the species and abundance of the metallic elements in each group fraction were determined by inductively coupled plasma atomic emission spectroscopy (ICP-AES), and their distribution was obtained by calculating the metallic proportion.

\subsubsection{Occurrence of metallic elements in Liaohe super- heavy oil}

The following experiments were conducted to determine the occurrence of the metallic elements in Liaohe super-heavy oil:

1) The super-heavy oil was completely dissolved in toluene by heating and refluxing, and the mixture was extracted with a mixture of deionized water and an equivalent volume of anhydrous ethanol. Anhydrous ethanol was used to increase the separation efficiency. The extraction was repeated twice to obtain a water phase and an oil phase. Then, the toluene in the oil phase was evaporated in an oil bath at constant temperature. Subsequently, the contents of metallic elements in the water phase and the oil phase samples were measured by ICP-AES to determine the proportions of the water-soluble (inorganic) and oil-soluble (organic) metallic elements.

2) The super-heavy oil was completely dissolved in toluene by heating and refluxing. The mixture was then extracted with acetic acid solution and an equivalent volume of anhydrous ethanol. After three cycles of extraction, the toluene in the oil phase was evaporated by heating. The contents of metallic elements in the aqueous acetic acid phase and oil phase samples were measured by ICP-AES to determine the proportion of the ionized and non-ionized metallic elements in an acidic environment. Enough acetic acid was added to complete the demetallization reaction.

3) The super-heavy oil was completely dissolved in chloroform by heating and refluxing. The mixture was then adsorbed with neutral alumina, and the solid phase was separated through filtration. The solid phase was extracted with acetonitrile using a Soxhlet extractor to obtain the porphyrins. The abundance of metallic elements in the acetonitrile extract was measured to determine the proportion of metallic elements existing in the form of metalloporphyrins in the super-heavy oil.

\section{Results and discussion}

\subsection{Properties of Liaohe super-heavy oil}

Table 1 presents the properties of Liaohe super-heavy oil. The table shows that the density, viscosity, and acid number of the oil are all significantly higher than to those of conventional crude oil (usually its specific gravity, viscosity and total acid number is less than $0.95,10 \mathrm{~Pa} \cdot \mathrm{s}$ and $1 \mathrm{mg}$ $\mathrm{KOH} / \mathrm{g}$, respectively). The total acid number is $12.76 \mathrm{mg}$ $\mathrm{KOH} / \mathrm{g}$, indicating high content of petroleum acids. The four metallic elements, namely calcium, nickel, iron, and manganese, are all more than $10 \mu \mathrm{g} / \mathrm{g}$ in abundance, and the total content of metallic elements is more than $700 \mu \mathrm{g} / \mathrm{g}$, in which calcium is the most dominant metallic element with a content of $524 \mu \mathrm{g} / \mathrm{g}$.

Table 1 Properties of Liaohe super-heavy oil sample

\begin{tabular}{cc}
\hline Item & Value \\
\hline$\rho_{20}, \mathrm{~g} / \mathrm{cm}^{3}$ & 1.0003 \\
$\eta_{50}, \mathrm{~Pa} \cdot \mathrm{s}$ & 158 \\
Water, $\mathrm{wt} \%$ & 2.34 \\
Salt, $\mathrm{mg} / \mathrm{L}$ & 9.4 \\
Total acid number, $\mathrm{mg} \mathrm{KOH} / \mathrm{g}$ & 12.76 \\
$\mathrm{Ca}, \mu \mathrm{g} / \mathrm{g}$ & 524 \\
$\mathrm{Ni}, \mu \mathrm{g} / \mathrm{g}$ & 125 \\
$\mathrm{Fe}, \mu \mathrm{g} / \mathrm{g}$ & 47.5 \\
$\mathrm{Mn}, \mu \mathrm{g} / \mathrm{g}$ & 17.4 \\
\hline
\end{tabular}




\subsection{Distribution of metallic elements in group fractions of super-heavy oil}

The Liaohe super-heavy oil was separated into four fractions (saturates, aromatics, resins and asphaltenes) (Fig.1) by the separation procedures described in Section 2.2.1, without loss of metallic elements because of the absence of solid adsorbent.

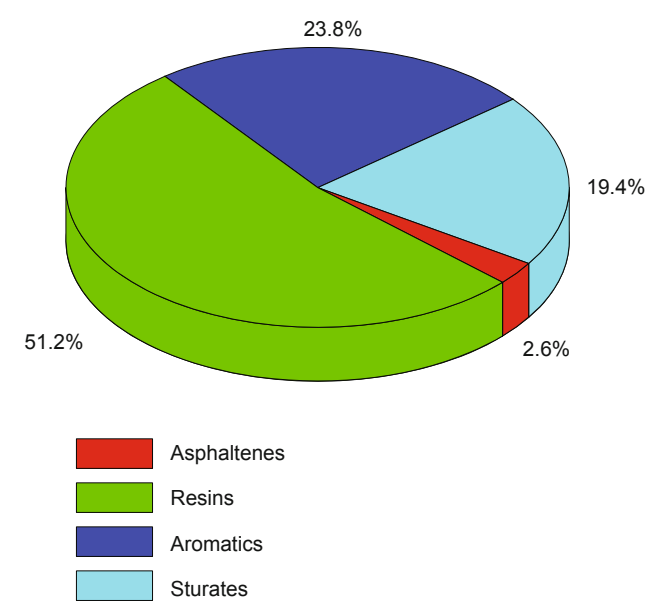

Fig. 1 Mass distribution of SARA of super-heavy oil

Fig. 1 shows that the resin content in the super-heavy oil is $51.2 \mathrm{wt} \%$, substantially higher than that in conventional crude oil (usually less than $30 \mathrm{wt} \%$ ). Fig. 2 shows that calcium is the dominant metallic element in the four fractions, and its content in asphaltenes is $7,920 \mu \mathrm{g} / \mathrm{g}$. The total content of the four metallic elements in SARA decreases in the order of asphaltenes $>$ resins $>$ aromatics $>$ saturates.

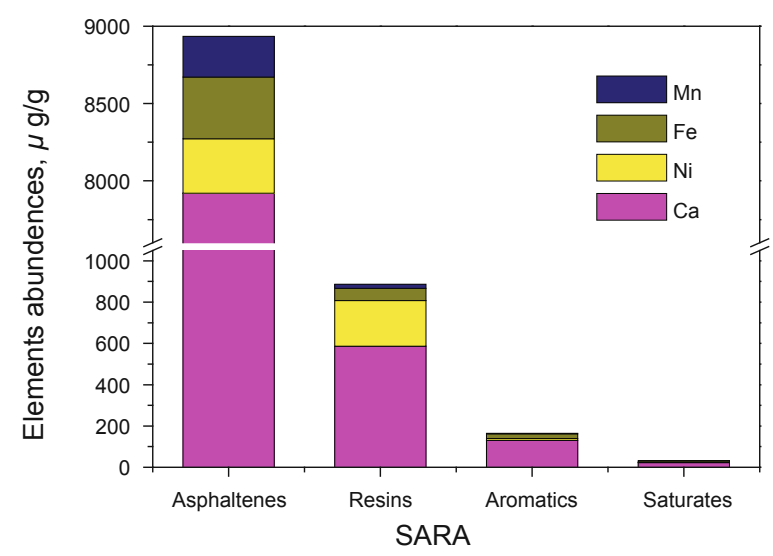

Fig. 2 Abundance of metallic elements in four fractions of super-heavy oil

The distribution of the metallic elements in four fractions (Fig. 3) can be expressed as follows:

$$
X=\frac{C_{i} \cdot m_{i}}{\sum_{i=1}^{4} C_{i} \cdot m_{i}} \times 100
$$

where $X$ is the percentage of each metallic element in component $i ; C_{i}$ is the concentration $(\mu \mathrm{g} / \mathrm{g})$ of the metallic elements in component $i$; and $m_{i}$ is the total mass (g) of the group component $i$.

Fig. 3 shows that the percentages of the total calcium, nickel, iron, and manganese in the resin were $57.5 \%$, $90.4 \%, 63.6 \%$, and $61.3 \%$, respectively, because of the large proportion of resin $(51.2 \mathrm{wt} \%)$.

\subsection{FT-IR analysis of SARA of Liaohe super-heavy oil}

The significant differences in the abundance of metallic elements in SARA fractions may be closely related to SARA chemical structure. Therefore, Fourier transform-infrared spectroscopy (FT-IR) analysis was conducted to characterize the functional groups in each fraction.

The absorption peak $\left(1,707 \mathrm{~cm}^{-1}\right)$ in Fig. 4 was attributed to the stretching vibration of $-\mathrm{COOH}$, and the absorption peak around $1,606 \mathrm{~cm}^{-1}$ was related to the stretching vibration of phenyl, amide, and $-\mathrm{COOM}^{+}$groups. The high contents of metallic elements in asphaltenes may be one of the important factors responsible for the high absorption peak $\left(1,606 \mathrm{~cm}^{-1}\right)$ seen in Fig. 4(a). The dramatic change in the absorption peaks (around 1,707 and 1,606 $\mathrm{cm}^{-1}$ ) demonstrated that the carboxylic acid content increased in the order of asphaltenes $<$ resins $<$ aromatics $<$ saturates, while the carboxylic salt contents showed an opposite trend, which may be related to the polarity of the fractions and the result is shown in Fig. 4.

Because of their corrosivity and the commercial value they cause, petroleum acids have attracted the attention of many researchers, and numerous techniques have been developed worldwide for separation and removal of petroleum acids from crude oil or distillates, including catalytic hydrogenation (Grande and Sorlie, 2000), alkaline neutralization (Varadaraj and Savage, 2000), thermal decomposition (Blum et al, 1998), solvent extraction (Mediaas et al, 2003), and adsorption separation (Gaikar and Maiti, 1996). The structure of naphthenic acid can be determined using a mass spectrometer by different ionization methods, such as chemical ionization (Dzidic et al, 1988), electron ionization (St John et al, 1998), fast atom bombardment (Gallegos, 1987), electrospray ionization (Qian et al, 2001; Barrow et al, 2003; Hughey et al, 2007; Gabryelski and Froese, 2003; Huang et al, 2007; Fu et al, 2007), and atmospheric pressure chemical ionization (Hsu et al, 2000). In our previous study (Wu and Zhu, 2009), petroleum acids were separated from Liaohe superheavy oil by using the solvent extraction method, and their structures were characterized by electrospray ionization mass spectrometry (ESI-MS). The ESI-MS results showed that the petroleum acids in Liaohe super-heavy oil were composed of $13.6 \%$ fatty acids and $86.4 \%$ mono- and multi-ring naphthenic acids.

\subsection{Distribution of metallic elements with different occurrence forms in Liaohe super-heavy oil}

On the basis of the experimental results from Section 


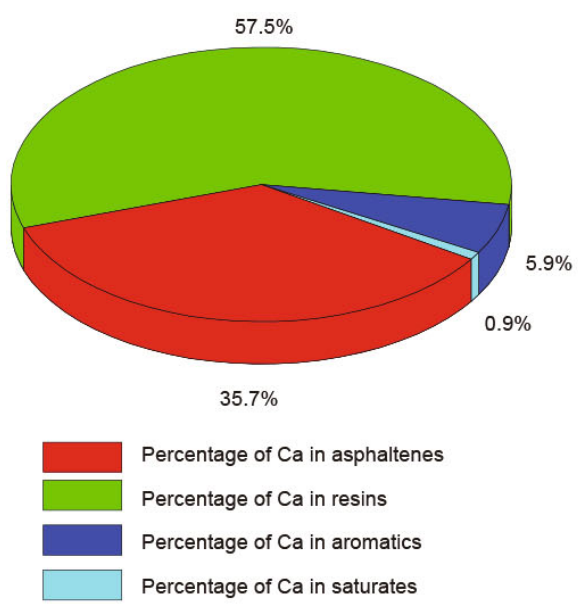

(a)

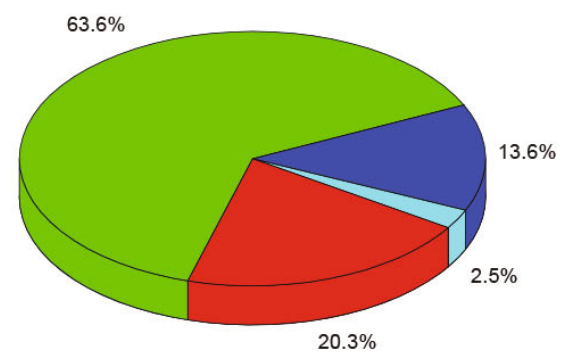

Percentage of $\mathrm{Fe}$ in asphaltenes

Percentage of $\mathrm{Fe}$ in resins

Percentage of $\mathrm{Fe}$ in aromatics

Percentage of $\mathrm{Fe}$ in saturates

(c)

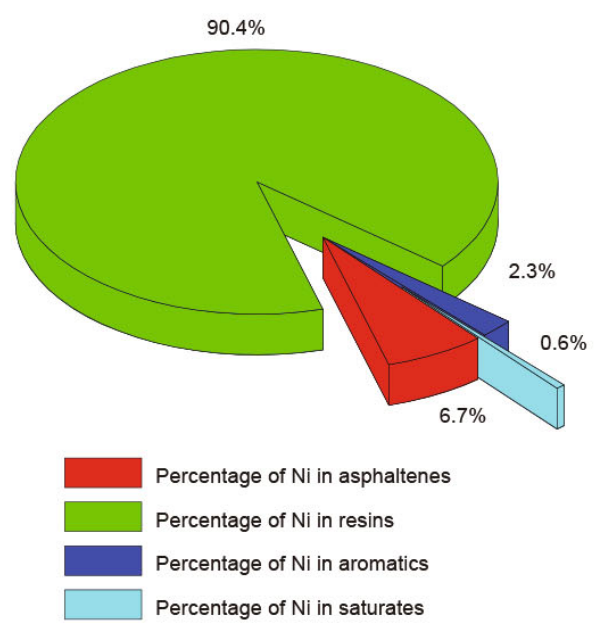

(b)

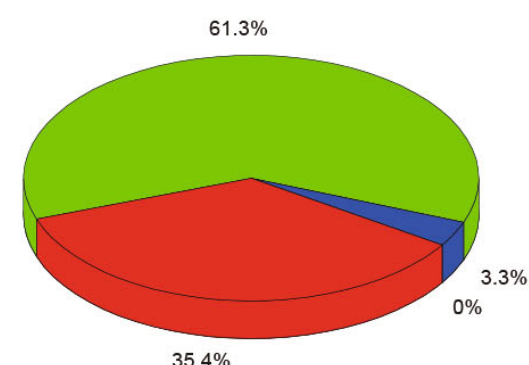

Percentage of $\mathrm{Mn}$ in asphaltenes

Percentage of $\mathrm{Mn}$ in resins

Percentage of $\mathrm{Mn}$ in aromatics

Percentage of $\mathrm{Mn}$ in saturates

(d)

Fig. 3 Percentage of the total metallic elements $(\mathrm{Ca}, \mathrm{Ni}, \mathrm{Fe}, \mathrm{Mn})$ in four fractions of super-heavy oil

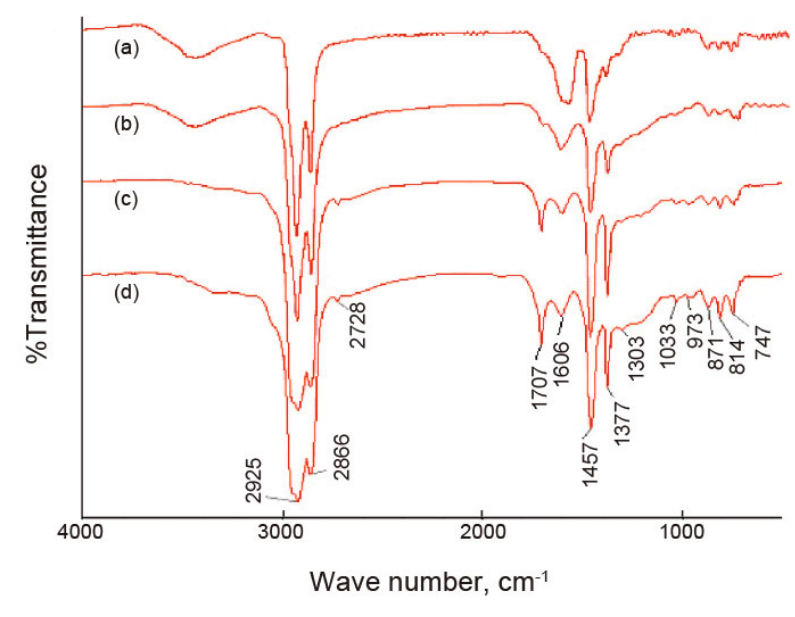

Fig. 4 FT-IR spectra of SARA fractions of super-heavy oil (a) Asphaltenes; (b) Resins; (c) Aromatics; (d) Saturates

2.2.2, the metallic elements of calcium, nickel, iron, and manganese in the Liaohe super-heavy oil occur in four forms, namely, inorganic salts, metal salts of petroleum acids, metalloporphyrins, and non-metalloporphyrins (Tables 2).
The percentage of each metallic element $\mathrm{Y}$ in the crude oil was calculated using Formula (2):

$$
Y=\frac{C_{j} \cdot m_{j}}{C \cdot m} \times 100
$$

where $C_{j}$ is the concentration $(\mu \mathrm{g} / \mathrm{g})$ of the metallic elements in sample $j ; C$ is the concentration $(\mu \mathrm{g} / \mathrm{g})$ of the metallic elements in the super-heavy oil; $m_{j}$ is the total mass $(\mathrm{g})$ of the sample $j$; and $m$ is the total mass ( $\mathrm{g}$ ) of super-heavy oil.

Table 2 shows that $87.1 \%$ of calcium, $99.8 \%$ of nickel, $93.8 \%$ of iron, and $97.9 \%$ of manganese still remained in the super-heavy oil after deionized water extraction, indicating that the majority of these metallic elements are in the form of oil-soluble compounds. Furthermore, a minority of these metallic elements are in the form of water-soluble inorganic salts. Therefore, removing these metallic elements by using a conventional electric desalting device is difficult. After extraction with $1 \%$ acetic acid solution, all manganese and $99.2 \%$ of calcium in the super-heavy oil were removed, but all the nickel and $88.8 \%$ of the iron remained in the oil phase. This phenomenon occurred because the organic compounds of calcium and manganese in the super-heavy oil are mainly 
Table 2 Abundance of metallic elements in the sample before and after solution extraction

\begin{tabular}{|c|c|c|c|c|c|c|c|c|}
\hline \multirow{2}{*}{ Sample } & \multicolumn{4}{|c|}{$\begin{array}{c}\text { Element abundances } \\
\mu \mathrm{g} / \mathrm{g}\end{array}$} & \multicolumn{4}{|c|}{$Y, \%$} \\
\hline & $\mathrm{Ca}$ & $\mathrm{Ni}$ & $\mathrm{Fe}$ & $\mathrm{Mn}$ & $\mathrm{Ca}$ & $\mathrm{Ni}$ & $\mathrm{Fe}$ & $\mathrm{Mn}$ \\
\hline Untreated super-heavy oil & 524 & 125 & 47.5 & 17.4 & l & l & l & 1 \\
\hline Super-heavy oil after deionized water extraction & 461 & 126 & 45.0 & 17.2 & 87.1 & 99.8 & 93.8 & 97.9 \\
\hline Super-heavy oil after acid-containing water extraction & 4.4 & 125 & 42.2 & 0 & 0.8 & 100 & 88.8 & 0 \\
\hline Acetonitrile extracts & 15.9 & 59.9 & 38.8 & 0 & 1.3 & 20.7 & 35.4 & 0 \\
\hline
\end{tabular}

metal salts of petroleum acids, which could be easily ionized and transferred into aqueous phase under acidic conditions. Table 2 also shows that calcium, nickel, and iron can exist as metalloporphyrins, in which the metalloporphyrin forms of nickel and iron account for $20.7 \%$ and $35.4 \%$ of the total nickel and iron contents, respectively. However, only $1.3 \%$ of the total calcium is in the form of metalloporphyrin in the super-heavy oil.

Based on the above analysis, we obtained the distribution of the four metallic elements with different occurrences (Fig. $5)$.

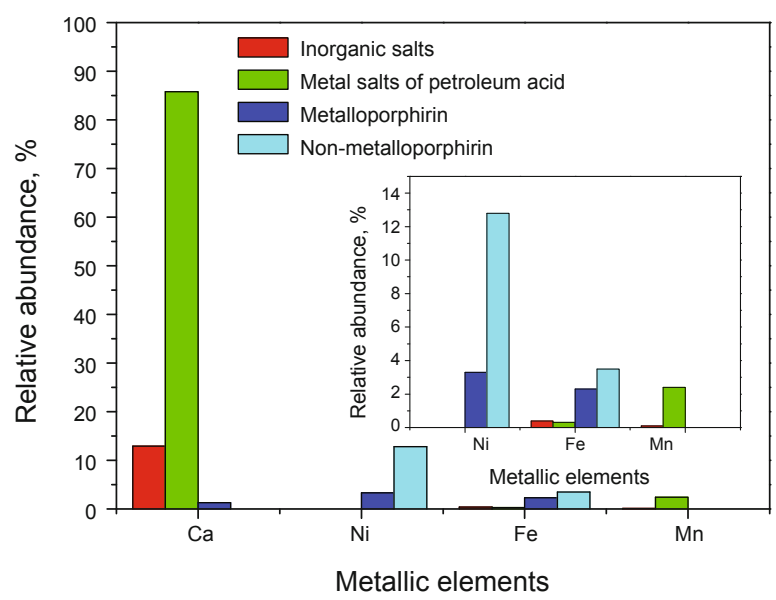

Fig. 5 Distribution of metallic elements with different forms in super-heavy oil

The four metallic elements have different occurrences and distributions, and iron has four types. Calcium and manganese are mainly in the form of metal salts of petroleum acids, and nickel is mainly in the form of non-metalloporphyrins. Only $13 \%$ of the total calcium is in form of inorganic salts. Evidently, the metal salts of petroleum acids are more abundant compared with other forms.

The metallic elements in the form of water-soluble inorganic salts are easily removed by crude oil pretreatment in an electric desalting device. However, the metallic elements in the form of oil-soluble compounds are difficult to remove. Therefore, the efficient removal of the metallic elements from oil-soluble compounds is the key factor to the subsequent processing of super-heavy oil. Demetallization methods can be classified into three types, namely, physical, chemical, and catalytic hydroprocessing methods. Currently, hydrodemetallization (HDM) has become an important technology to reduce the heteroatom contents and to improve the product quality (Rana et al, 2007). However, the application of HDM in super-heavy oil is unacceptable in terms of cost because highly abundant metallic elements demand large amounts of hydrogenation catalysts. The solvent deasphalting method (Seki and Kumata, 2000; Zhao et al, 2007) can indirectly remove nitrogen, sulfur, and oxygen (NSO) containing compounds and metallic elements in superheavy oils. However, the high content of resins in superheavy oils result in low demetallization efficiencies. Previous studies (Wu et al, 2006) have demonstrated that more than $95 \%$ of calcium and $100 \%$ of manganese, which exist mainly as metal salts of petroleum acids and inorganic salts, can be possibly removed using a demetallization agent under proper electric desalting conditions. The removal efficiency of iron is inconsistent because it occurs in all four forms. Nickel in metalloporphyrins and non-metalloporphyrins is also difficult to remove. Therefore, a single technology is inadequate to achieve the desired results for super-heavy oil demetallization. A combined demetallization method may be an effective alternative.

\section{Conclusions}

1) The group fractions can be effectively separated from super-heavy oil by solvent extraction. The super-heavy oil contains $2.6 \% n$-heptane asphaltenes, $51.2 \%$ resins, $23.8 \%$ aromatics, and $19.4 \%$ saturates.

2) The abundance of the four metallic elements, namely calcium, nickel, iron, and manganese, decrease from asphaltenes, resins, aromatics to saturates. This trend relates to the changes in the polarities of each fraction. The abundance of calcium, nickel, iron, and manganese are highest in asphaltenes, which were measured at 7,920, 352, 400 , and $263 \mu \mathrm{g} / \mathrm{g}$, respectively. The percentages of the total calcium, nickel, iron, and manganese in the resin were $57.5 \%$, $90.4 \%, 63.6 \%$, and $61.3 \%$, respectively, because of the large proportion of resin $(51.2 \mathrm{wt} \%)$.

(3) The calcium and manganese mainly exist in the form of metal salts of petroleum acids, and nickel and iron mainly exist as non-metalloporphyrin.

\section{Acknowledgement}

This work was supported by the National Natural Science Foundation of China (No. 20576075 and 21206194).

\section{References}

Barrow M P, McDonnell L A, Feng X, et al. Determination of the nature of naphthenic acids present in crude oils using nanospray Fourier 
Transform ion cyclotron resonance mass spectrometry: the continued battle against corrosion. Analytical Chemistry. 2003. 75(4): 860-866

Bartholomew C H. Mechanisms of catalyst deactivation. Applied Catalysis A: General. 2001. 212(1-2): 17-60

Blum S C, Olmstead N and Bearden R. Thermal decomposition of naphthenic acids. 1998. US Patent: 5820750

Dzidic I, Somerville A C, Raia J C, et al. Determination of naphthenic acids in California crudes and refinery wastewaters by fluoride ion chemical ionization mass spectrometry. Analytical Chemistry. 1988. 60(13): 1318-1323

El-Sabagh S M. Occurrence and distribution of vanadyl porphyrins in Saudi Arabian crude oils. Fuel Processing Technology. 1998. 57(1): $65-78$

Fu X Q, Tian S B, Hou S D, et al. Study on the structure and composition of petroleum acids in the Penglai and Sudan high acid crude oil. Chemical Engineering of Oil \& Gas. 2007. 36(6): 507-510 (in Chinese)

Gabryelski W and Froese K L. Characterization of naphthenic acids by electrospray ionization high-field asymmetric waveform ion mobility spectrometry mass spectrometry. Analytical Chemistry. 2003. 75(17): 4612-4623

Gaikar V G and Maiti D. Adsorptive recovery of naphthenic acids using ion-exchange resins. Reactive \& Functional Polymers. 1996. 31: 155-164

Gallegos E J. Gas chromatography/fast-atom bombardment mass spectrometry of carboxylic acids. Journal of Chromatographic Science. 1987. 25(7): 296-301

Grande K and Sorlie C. Process for removing essentially naphthenic acids from a hydrocarbon oil. 2000. US Patent: 6063266

Hou D G and Wang X Q. Study on distribution and composition of calcium in some Chinese crudes. Acta Petrolei Sinica (Petroleum Processing Section). 2000. 16(1): $54-59$ (in Chinese)

Hsu C S, Dechert G J, Robbins W K, et al. Naphthenic acids in crude oils characterized by mass spectrometry. Energy \& Fuels. 2000. 14(1): 217-223

Huang S K, Tian S B, Liu Z L, et al. Determination of the structure and composition of petroleum acids in the diesel fractions of crude oil with high acid number. Petroleum Processing and Petrochemicals. 2007. 38(4): 51-55 (in Chinese)

Hughey C A, Galasso S A and Zumberge J E. Detailed compositional comparison of acidic NSO compounds in biodegraded reservoir and surface crude oils by negative ion electrospray Fourier transform ion cyclotron resonance mass spectrometry. Fuel. 2007. 86(5-6): 758768

Krasnikov S A, Preobrajenski A B, Sergeeva N N, et al. Electronic structure of $\mathrm{Ni}(\mathrm{II})$ porphyrins and phthalocyanine studied by soft X-ray absorption spectroscopy. Chemical Physics. 2007. 332(2-3): 318-324

Liu C G, Xu Z H, Zhu J H, et al. Study on occurrence modes of calcium in crude oil of Dagang oilfield. Petrochemical Technology. 2000. 29(11): 866-868, 840 (in Chinese)

Luo Y T, Zhu J H and Zhang S J. Relationship of ash in coke with properties of coking feedstock. Journal of the University of Petroleum, China. 2005. 29(3): 116-118 (in Chinese)

McKenna A M, Purcell J M, Rodgers R P, et al. Identification of vanadyl porphyrins in a heavy crude oil and raw asphaltene by atmospheric pressure photoionization fourier transform ion cyclotron resonance (FT-ICR) mass spectrometry. Energy Fuels. 2009. 23(4): 2122-2128

Mediaas H, Grande V K, Hustad B M, et al. The acid-IER method - a method for selective isolation of carboxylic acids from crude oils and other organic solvents. SPE 80404. 2003

Qian K, Robbins W K, Hughey C A, et al. Resolution and identification of elemental compositions for more than 3000 crude acids in heavy petroleum by negative-ion microelectrospray high-field Fourier transform ion cyclotron resonance mass spectrometry. Energy \& Fuels. 2001. 15(6): 1505-1511

Rana M S, Ancheyta J, Rayo P, et al. Heavy oil hydroprocessing over supported NiMo sulfided catalyst: An inhibition effect by added H2S. Fuel. 2007. 86(9): 1263-1269

Seki H and Kumata F. Structural change of petroleum asphaltenes and resins by hydrodemetallization. Energy Fuels. 2000. 14(5): 980-985

St John W P, Rughani J, Green S A, et al. Analysis and characterization of naphthenic acids by gas chromatography-electron impact mass spectrometry of tert.-butyldimethylsilyl derivatives. Journal of Chromatography A. 1998. 807(2): 241-251

Trimm D L. The regeneration or disposal of deactivated heterogeneous catalysts. Applied Catalysis A: General. 2001. 212(1-2): 153-160

Varadaraj R and Savage D W. Process for neutralization of petroleum acids (LAW810). 2000. US Patent: 6030523

Wu B C and Zhu J H. Identification of petroleum acids in Liaohe superheavy oil. Petroleum Science. 2009. 6(4): 433-437

Wu B C, Zhu J H, Wang J, et al. Technique for high-viscosity crude oil demetallization in the Liaohe oil field. Energy Fuels. 2006. 20(4): 1345-1349

Wu J Y, Liu J P and Weng H X. Properties of calcium in Kelamayi residue. Journal of East China University of Science and Technology. 2001. 27(4): 344-348 (in Chinese)

Xu H, Yu D Y, Wang Z X, et al. Study of the catalytic hydrodemetalization of nickel and vanadium porphyrins. Acta Petrolei Sinica (Petroleum Processing Section). 2001. 17(4): 18-23 (in Chinese)

Zhao S Q, Xu C M, Xu Z M, et al. Deep separation method and processing system for the separation of heavy oil. U.S. patent No. 0007168 A1. 2007

Zhu Y X and Wang X Q. The study of calcium content and its distribution in domestic crude. Acta Petrolei Sinica (Petroleum Processing Section). 1998. 14(3): 57-61 (in Chinese)

(Edited by Zhu Xiuqin) 